\title{
Stability and Functionality of Grape Pomace Used as a Nutritive Additive During Extrusion Process
}

\author{
Bibi S, Kowalski RJ, Zhang S, Ganjyal GM and Zhu MJ*
}

School of Food Science, Washington State University, Pullman, WA 99164, USA

\begin{abstract}
Grape pomace (GP) is a major byproduct of wine and juice industry, rich in polyphenolics with demonstrated health benefits. Extrusion processing for development of healthy and quality GP supplemented cornstarch snack foods was evaluated using response surface methodology. The retainability of polyphenolic content and antioxidant activity after extrusion processing were further assessed. The processing variables were feed moisture (16, 20, and $24 \pm 0.2 \%$ w.b.), screw speed $(150,200$, and 250 $\mathrm{rpm})$, and the level of GP supplementation ( 0,5 , and $10 \% \mathrm{w} / \mathrm{w})$. Extrudates with $5 \%$ GP and $16 \pm 0.2 \%$ feed moisture had a high overall expansion ratio of $3.83 \pm 0.14$, and overall low density $\left(0.11 \pm 0.00 \mathrm{~g} / \mathrm{cm}^{3}\right)$. Total polyphenolic content (TPC) of the extrudates (5\% GP, and $16 \%$ feed moisture) extruded at 150 and $250 \mathrm{rpm}$ retained up to $74.1 \%$ and $78.57 \%$ respectively, while TPC was retained at $95 \%$ when extruded under $200 \mathrm{rpm}$ with $10 \% \mathrm{GP}$ and $16 \%$ feed moisture. Additionally, the total antioxidant activity and 2,2-diphenyl-1-picrylhydrazyl scavenging activity of the $5 \%$ GP extrudates retained $98 \%$ after extrusion processing. Moreover, polyphenolic extract of $5 \%$ GP extrudates suppressed reactive oxygen species in Caco-2 cells induced by hydrogen peroxide. In conclusion, GP incorporation in cornstarch extrudates improved both the physicochemical quality as well as nutritional value of products. Our study indicates that GP can be effectively incorporated into extruded foods by providing enhanced nutritional value without losing the expansion characteristics.
\end{abstract}

Keywords: Grape pomace; Extrudates; Expansion; Polyphenolics; Antioxidant activity; Reactive oxidative species

\section{Introduction}

Grape is the $4^{\text {th }}$ largest fruit crop in the world with a production of 67 million tons per year [1]. Grapes are generally cultivated for the wine production with about $80 \%$ of the global grape production being used in the wine industry [2]. After the juicing process of grapes, huge amounts of the grape pomace (GP), consisting of seeds, skin and stems is obtained as the byproduct. GP is currently used as animal feed because of its protein value, as a fertilizer, and as a source for extraction of bioactive compounds [3,4]. GP is a rich source of polyphenolic compounds including gallic acid, catechin, epicatechin, and proanthocyanins among others [5]. GP also contains substantial amount of non-digestible fiber (60\%-70\%), essential fatty acids (13\%$19 \%)$, proteins $(11 \%)$, as well as non-phenolic tocopherols, betacarotene, and minerals [6,7]. The polyphenolics from GP are known for their antioxidant and anti-inflammatory effects [8,9], which demonstrate preventive effects on cancer [10], cardiovascular diseases [11], and inflammatory bowel disease [12]. The GP polyphenolics have been used in food technology as antioxidants to inhibit the oxidation of fish lipids, frozen fish muscle, and fish oil [13]. It is also used as a source of dietary fiber and antioxidant to enhance functionality and shelf life of yogurt and salad dressing [14], and ingredient in baking products [15].

As another alternative usage, GP has been used in extrusion cooking [16], by mixing with barley flour at levels of $2 \%-10 \%(w / w)$. However, using response surface methodology, product responses including bulk density, expansion, texture, and color were greatly affected by inclusion of GP and temperature of the extruder [16]. The GP barley flour extrudates with $2 \% \mathrm{GP}$ (at $160^{\circ} \mathrm{C}, 200 \mathrm{rpm}$ ) had higher preferences for overall product quality, while increasing GP proportion above $6 \%$ reduced expansion [16]. Extrusion processing also reduced the total phenolic content (TPC) of the GP barley flour extrudates compared to the raw material [17]. However, both of these studies lack a reasonable explanation of the positive interactions between GP and barley flour, which can greatly affect the textural properties and is evident from our recent findings on carrot and cherry pomace incorporation in cornstarch extrudates $[18,19]$. Furthermore, feed moisture can also affect the textural as well as nutritional quality of the extruded products. Extrusion of GP with white sorghum (at ratio of $30: 70 \mathrm{w} / \mathrm{w}$, barrel temperature of $170^{\circ} \mathrm{C}$ and screw speed of $200 \mathrm{rpm}$ ) with a moisture content of $45 \%$ resulted in $120 \%$ increase in monomer contents of the polyphenolics in GP extrudates [20]. All these suggest that extruded products can serve as a great vehicle for the delivery of beneficial nutrients of the GP, as extrusion is a high shear, high pressure, and short time processing technology [21], proven to help improve digestibility and nutrient bioavailability $[20,22]$, and to have distinct textural properties [23]. However, both the nutritional and textural quality of the extrudates is highly affected by the operational process including screw speed, feed moisture and raw material composition used [24], which remain unclear for GP cornstarch extrudates.

Expansion, an important quality parameter of the extruded puffed products, is greatly affected by the feed moisture content and composition of feed $[18,19,25]$. Cornstarch, widely used in extrusion cooking, undergoes gelatinization and mechanical degradation during extrusion, and expands well, while other raw ingredients such as proteins, added sugars, lipids, fiber and moisture generally tend to reduce expansion $[24,26]$. The cornstarch expanded products are usually energy dense, with high glycemic index and low nutrients (vitamins, minerals, proteins and fiber). Nutritional value of these products can be improved via incorporation of bioactive compounds and fibers from

*Corresponding author: Mei-Jun Zhu, School of Food Science, Washington State University, Pullman, WA 99163, USA, Tel: 509-335-4016, Fax: 509-3354815; E-mail: meijun.zhu@wsu.edu

Received June 08, 2017; Accepted June 26, 2017; Published July 03, 2017

Citation: Bibi S, Kowalski RJ, Zhang S, Ganjyal GM, Zhu MJ (2017) Stability and Functionality of Grape Pomace Used as a Nutritive Additive During Extrusion Process. J Food Process Technol 8: 680. doi: 10.4172/2157-7110.1000680

Copyright: (c) 2017 Bibi S, et al. This is an open-access article distributed under the terms of the Creative Commons Attribution License, which permits unrestricted use, distribution, and reproduction in any medium, provided the original author and source are credited. 
legumes, fruits, and vegetables [23]. Studies on the incorporation of pomace into extruded products showed that increased pomace levels beyond a certain level had negative effect on the expansion quality $[16,17,20,27,28]$. However, recent studies indicated that carrot and cherry pomace incorporation into cornstarch extrudates resulted in better expansion and nutritional quality $[18,19]$. The objective of the current study was to examine the impact of GP incorporation on the quality of the cornstarch extrudates during extrusion processing and to produce a nutrient enhanced extruded product with good quality attributes.

\section{Materials and Methods}

\section{Feed material}

Cornstarch (native dent cornstarch with $23 \%$ amylose) was obtained from Tate \& Lyle Hoffman Estates, IL, USA). White GP was received from Woodward Canyon Winery (Lowden, WA, USA) that mainly contained Chardonnay grape skins, seeds, as well as some stems. The GP was freeze-dried in VirTis freeze drier (Vertis Comp. Gardiner, NY, USA) and ground using a cyclone mill (Model\# 3010-060, UDY Corp. Fort Collins, CO, USA). Particle size of the white GP was determined through the U.S.A standard test sieves of 75, 125, 150, 212 and $250 \mu \mathrm{m}$ (Model\# 78-700, Field master, Science First, Yulee, FL, USA). The GP bulk density was determined by measuring weight and volume of the GP content using standard graduated cylinder, and expressed in grams per cubic centimeter [18]. The moisture (oven drying), ash, protein content (Kjeldahl, protein factor: 6.25), and total sugar (using Fehling's reagents) were determined by the official methods (number 968.21, 945.18, and 974.06, respectively) of AOAC [29]. Total dietary fiber content was determined using Sigma total dietary assay kit (TDF-A100 Sigma, St. Louis, MO, USA).

\section{Feed mixture preparation}

The cornstarch and GP $(0,5$ and $10 \% \mathrm{w} / \mathrm{w})$ were mixed in a Hobart mixer (Model \#A-200, Hobart, OH, USA) and equilibrated at three moisture levels: 16,20 , and $24 \pm 0.2$ (\% w.b.) by adding the calculated amount of water. The feed mixtures were then stored in airtight plastic containers at $4^{\circ} \mathrm{C}$ overnight.

\section{Processing conditions of extruder and process response}

A $20 \mathrm{~mm}$ co-rotating twin-screw extruder (Model\# TSE 20/40, CW Brabender, S. Hackensack, NJ, USA) with a length of $400 \mathrm{~mm}$ and the length to diameter (L/D) ratio of 20:1, was used for all the extrusion experiments. The temperature profile of the four independent zones of the extruder were kept constant at $50^{\circ} \mathrm{C}, 100^{\circ} \mathrm{C}, 140^{\circ} \mathrm{C}$, and $140^{\circ} \mathrm{C}$. A cylindrical die with a diameter of $3 \mathrm{~mm}$ was used. The feed rate of the material was fixed at $3.25 \mathrm{~kg} / \mathrm{h}$ using a calibrated twin-screw volumetric feeder (Model\# 15-37-000, CW Brabender Technologie, NJ, USA). The screw speeds were varied from $150 \mathrm{rpm}$ to $250 \mathrm{rpm}$. These extrusion parameters were selected based on the literature data and our previous extrusion research experiments [19].

The premixed cornstarch and GP combinations were extruded as per the experimental design. After $5 \mathrm{~min}$, when the extruder attained the stable conditions of pressure, torque and output flow, extrudates were collected. The collected extrudates were dried in a convection oven (Model\# 414004-568, VWR International, LLC, PA, USA) at $45^{\circ} \mathrm{C}$ for $18 \mathrm{~h}$. The extrudates had final average moisture of $4 \%-6 \%$ (w.b.) and were stored in airtight plastic bags at $4^{\circ} \mathrm{C}$ until analysis. During processing, continuous data from the extruder, including die pressure, motor torque, and zone temperature, were recorded using
Data Acquisition System for ATR and Intelli-Torque (CW Brabender, S. Hackensack, NJ, USA). The average of 10 data points, being taken at 20 second intervals during stable conditions, was used to calculate the specific mechanical energy (SME), motor torque, and die pressure according to previously reported method [30].

\section{Product response}

Expansion ratio (ER): Radial expansion was determined by measuring the diameter of 10 randomly chosen extrudates from one processing condition with a calipers (Mitutoyo America Corp., Aurora, IL, USA) according to the method reported previously [25]. For each experimental trial, two data points per single extrudate, with a total of 10 random extrudates, were taken and the mean diameter was calculated. ER was determined by dividing the mean diameter of the extrudates by the die diameter $(3 \mathrm{~mm})$.

Unit density: Unit density of the extrudates was determined in triplicate through displacement of $1.0 \mathrm{~mm}$ diameter glass beads (General Laboratory Supply, Pasadena, TX, USA) according to the method reported previously [25]. Glass beads $(30 \mathrm{ml})$ were filled in a $50 \mathrm{ml}$ graduated cylinder, and the displacement of the beads by the extruded sample $(2.0 \mathrm{~g})$ was recorded. The density was equal to the sample mass divided by the sample volume.

Water absorption and water solubility index: Water absorption index (WAI) and water solubility index (WSI) were determined by the previously described procedure [31]. Briefly, a portion of milled extrudates $(2.5 \mathrm{~g})$ was taken in $50 \mathrm{ml}$ vial containing $30 \mathrm{ml}$ of $30^{\circ} \mathrm{C}$ distilled water. Samples were mixed for $30 \mathrm{~min}$ in a $30^{\circ} \mathrm{C}$ water bath and then centrifuged at $3,000 \times \mathrm{g}$ speed for $10 \mathrm{~min}$. The supernatant was removed and dried overnight. The weight of wet precipitate was recorded after $10 \mathrm{~min}$ for WAI. WAI was calculated as the ratio of the mass of the wet precipitate to the mass of the original dry weight. WSI was expressed as percentage of the overnight dried solid weight of the collected supernatant to the original sample weight.

Hardness: Hardness of the extrudates was determined by the previously reported method [32]. Briefly, texture analyzer TA.XT2i (Texture Technologies, Scarsdale, NY, USA) with a single-blade and a $25 \mathrm{~kg}$ load cell with a test speed of $1 \mathrm{~mm} / \mathrm{s}$ was used. The maximum force required to break an extrudate was recorded. Ten extrudates were analyzed per treatment and the mean peak force was reported.

Color: Color measurements were performed on milled extruded samples from all the trials, using a CM-5 spectrophotometer (Konica Minolta, NJ, USA) according to the method reported previously [28]. The color was recorded using a Hunter color scale as the mean of three $\mathrm{L}^{*}, a^{\star}$, and $b^{\star}$ readings, where $\mathrm{L}^{*}$ indicates lightness, $a^{\star}$ indicates redness, and $b^{*}$ indicates yellowness. A standard white and black calibration plate was used to equilibrate the spectrophotometer prior to color measurements.

Total polyphenolic compounds extraction and analysis: Total polyphenolics were extracted from raw material before processing and from extrudates after processing as previously reported [33]. Briefly, samples were defatted twice with $\mathrm{n}$-hexane at $70^{\circ} \mathrm{C}$ for $20 \mathrm{~min}$. Total polyphenols were extracted from $1 \mathrm{~g}$ of GP using $10 \mathrm{ml}$ of $80 \%$ ethanol that contained $1 \%$ formic acid $(\mathrm{v} / \mathrm{v})$ for $12 \mathrm{~h}$, and then centrifuged at $10,000 \times \mathrm{g}$ for $15 \mathrm{~min}$. The supernatants were collected and residue samples were re-extracted once under the same conditions. The TPC was determined by modified Folin-Ciocalteu assay in a 96-well plate format [34]. Briefly, $200 \mu \mathrm{l}$ of the extracts were mixed with $12.5 \mu \mathrm{l}$ of Folin-Ciocalteu reagent and then $37.5 \mu \mathrm{l} 20 \% \mathrm{Na}_{2} \mathrm{CO}_{3}$ in a 96-well 
plate. The plate was incubated at room temperature for $2 \mathrm{~h}$ when the absorbance was read at $760 \mathrm{~nm}$ on Synergy ${ }^{\text {Tix }} \mathrm{H} 1$ microplate reader (BioTek, Winooski, VT, US). Gallic acid was used to generate the standard curve. The TPC was expressed as milligrams of gallic acid equivalents per gram of dried weight (mg GAE/ g DW). TPC data was subjected to General Linear Model of Statistical Analysis System (2000) and was expressed as mean \pm standard error of mean. A significant difference was considered as $P \leq 0.05$.

Total anti-oxidant activity and 2,2-diphenyl-1-picrylhydrazyl (DPPH) free radical scavenging analysis: Assay was performed in a 96-well plate using previously published method with some modifications [35]. Briefly, $200 \mu \mathrm{l}$ of DPPH solution $(60 \mu \mathrm{M})$ (Sigma, St. Louis, MO, USA) was added to wells of 96-well plate containing 50 $\mu \mathrm{l}$ of diluted extracts of the raw mix and GP extrudates or gallic acid standard solution. After incubation for $90 \mathrm{~min}$ at room temperature, the DPPH scavenging activity was measured at $517 \mathrm{~nm}$ absorbance on Synergy $^{\text {max }} \mathrm{H} 1$ microplate reader (BioTek, Winooski, VT, US). The total antioxidant activity was expressed as $\mu \mathrm{g}$ GAE/g DW based on the gallic acid standard calibration curve. The DPPH radical scavenging activity expressed as percentage of inhibition was calculated using the formula:

$$
\text { Inhibition }(\%)=\frac{A_{\text {control }}-A_{\text {sample }}}{A_{\text {control }}} \times 100
$$

where,

\section{$A$ is the absorbances}

$A_{\text {control }}$ is reading without samples.

Effects of GP extrudates extracts on intracellular reactive oxygen species (ROS) production in CACO-2 human colonic epithelial cells: Caco-2 cell line was obtained from American Type Culture Collection (Manassas, VA, USA). The cells were grown in in Dulbecco's Modified Eagle's medium complete media: (DMEM, Sigma, St. Louis, MO, USA) supplemented with $10 \%$ fetal bovine serum (FBS, Sigma) and $1 \%$ penicillin-streptomycin (Sigma) at $37^{\circ} \mathrm{C}$ with $5 \% \mathrm{CO}_{2}$ in a humidified incubator. Intracellular ROS levels were measured using a cell-permeable fluorescent probe, 2,7-dichlorofluorescein diacetate (DCFH-DA) (Millipore, MA, USA) as previously described with some modifications [36]. Briefly, $100 \mathrm{l}$ of Caco- 2 cells $\left(5 \times 10^{5} \mathrm{cell} / \mathrm{ml}\right)$ were seeded in 96-well plate, and cultured in DMEM media with $10 \%$ FBS at $37^{\circ} \mathrm{C}$ with $5 \% \mathrm{CO}_{2}$ for $12 \mathrm{~h}$. Then, cells were pre-treated with $10 \mathrm{lof}$ the polyphenolic extracts in DMEM media for $12 \mathrm{~h}$. After washing with PBS once, the cells were incubated with $100 \mu \mathrm{l}$ of $10 \mu \mathrm{M}$ fresh DCFHDA in PBS for 30 min. Then the cells were washed with PBS once, and incubated with $100 \mu \mathrm{l}$ of PBS or $0.5 \mathrm{M} \mathrm{H}_{2} \mathrm{O}_{2}$ for $30 \mathrm{~min}$. Fluorescence of each well was measured at an excitation wavelength of $485 \mathrm{~nm}$ and an emission wavelength of $530 \mathrm{~nm}$ on Synergy ${ }^{\mathrm{mn}} \mathrm{H} 1$ microplate reader (BioTek, Winooski, VT, USA). All the values were normalized with the control (no extract no $\mathrm{H}_{2} \mathrm{O}_{2}$ ).

\section{Experimental design and statistical analysis}

Response surface methodology was used to investigate the effects of extrusion processing conditions on the process responses (SME, motor torque, and die pressure) and product responses (ER, unit density, hardness, WAI, WSI, and color) of the extrudates. The independent variables were feed moisture (16, 20, and $24 \pm 0.2 \%$ w.b.), screw speed (150 rpm, $200 \mathrm{rpm}$, and $250 \mathrm{rpm})$, and the GP level (0\%, 5\%, and $10 \%)$. A Box-Behnken design was used to determine the experimental conditions (Table 1). Data was subjected to regression analysis and a second-order polynomial regression model:

\begin{tabular}{|c|c|c|c|}
\hline Moisture (\%) & Corn Starch (\%) & GP (\%) & Screw Speed (rpm) \\
\hline 16 & 100 & 0 & 200 \\
\hline 16 & 100 & 0 & 200 \\
\hline 16 & 95 & 5 & 150 \\
\hline 16 & 95 & 5 & 150 \\
\hline 16 & 95 & 5 & 250 \\
\hline 16 & 95 & 5 & 250 \\
\hline 16 & 90 & 10 & 200 \\
\hline 16 & 90 & 10 & 200 \\
\hline 20 & 100 & 0 & 150 \\
\hline 20 & 100 & 0 & 150 \\
\hline 20 & 100 & 0 & 250 \\
\hline 20 & 100 & 0 & 250 \\
\hline 20 & 95 & 5 & 200 \\
\hline 20 & 95 & 5 & 200 \\
\hline 20 & 95 & 5 & 200 \\
\hline 20 & 95 & 5 & 200 \\
\hline 20 & 95 & 5 & 200 \\
\hline 20 & 95 & 5 & 200 \\
\hline 20 & 90 & 10 & 150 \\
\hline 20 & 90 & 10 & 150 \\
\hline 20 & 90 & 10 & 250 \\
\hline 20 & 90 & 10 & 250 \\
\hline 24 & 100 & 0 & 200 \\
\hline 24 & 100 & 0 & 200 \\
\hline 24 & 95 & 5 & 150 \\
\hline 24 & 95 & 5 & 150 \\
\hline 24 & 95 & 5 & 250 \\
\hline 24 & 95 & 5 & 250 \\
\hline 24 & 90 & 10 & 200 \\
\hline 24 & 90 & 10 & 200 \\
\hline
\end{tabular}

Table 1: Extrusion parameters and experimental design.

$$
Y=\beta_{0}+\sum_{i=1}^{3} \beta_{i} X_{i}+\sum_{i=1}^{3} \sum_{j=1}^{3} \beta_{i j} X_{i} X_{j}
$$

was used to fit the data for each response. Terms $\beta o, \beta, \beta_{i j}$ where $i=$ $j$, and $\beta_{i j}$ where $i \neq j$ are the coefficients for intercept, linear, quadratic, and interactive effects respectively. The term $Y$ is the response, and $X$ and $X_{j}$ are the independent variables of moisture, screw speed, and GP content. The responses were plotted as a function of two independent variables, keeping the other one constant at the middle level using Origin software (version 9.0, Origin Lab, Northhampton, MA, USA). A significant difference for a coefficient was considered as $P \leq 0.05$.

\section{Results and Discussion}

\section{GP is a potential nutritive adjunct ingredient for extrudates}

The GP had a moisture content of $13.96 \pm 0.14 \mathrm{~g} / 100 \mathrm{~g}$, ash content of $3.79 \pm 0.36 \mathrm{~g} / 100 \mathrm{~g}$, protein content of $7.15 \pm 0.12 \mathrm{~g} / 100 \mathrm{~g}$, total sugar content of $29.31 \pm 0.63 \mathrm{~g} / 100 \mathrm{~g}$, total dietary fiber content of $39.24 \pm$ $1.40 \mathrm{~g} / 100 \mathrm{~g}$, and crude fats content of $6.55 \pm 0.5 \mathrm{~g} / 100 \mathrm{~g}$. The bulk density of the GP was $0.48 \pm 0.01 \mathrm{~g} / \mathrm{cm}^{3}$. The particle size distribution in GP was $44.65 \%>250 \mu \mathrm{m}, 19.15 \%=250-212 \mu \mathrm{m}, 26.34 \%=212$ $150 \mu \mathrm{m}, 2.27 \%=150-125 \mu \mathrm{m}, 2.27 \%=125-175 \mu \mathrm{m}$, and $0.85 \%<75$ $\mu \mathrm{m}$. GP is rich in dietary fiber and other nutrients, and its combination in cornstarch expanded products can enhance the nutritional quality and market value of GP incorporated products. The percentage of fiber, sugar, protein and fat in the GP can interact with cornstarch forming complexes that can greatly affect the textural properties of the extrudates [37]. Though fiber was previously considered as inert 
Citation: Bibi S, Kowalski RJ, Zhang S, Ganjyal GM, Zhu MJ (2017) Stability and Functionality of Grape Pomace Used as a Nutritive Additive During Extrusion Process. J Food Process Technol 8: 680. doi: 10.4172/2157-7110.1000680

Page 4 of 9

material that reduces expansion $[38,39]$, recent studies indicated that carrot and cherry pomace in cornstarch can play an active role in the expansion of extrudates that is potentially due to the interaction between pomace fiber particles and starch $[18,19]$.

\section{Process response}

The process response parameters (SME, motor torque, and die pressure) indicate energy input to the materials in the extrusion process, which are affected by the extrusion processing inputs such as material composition (\%GP, moisture), and screw speed [21] Regression results obtained for SME, motor torque, and pressure are shown in Table 2. Feed moisture had a negative linear effect $(P \leq 0.01)$ on the die pressure. Screw speed had a positive linear effect $(P \leq 0.01)$ on SME but no effect on motor torque or die pressure was observed. Feed moisture, GP, and screw speed had negative quadratic effects on the SME. The interactive effects of moisture and GP were significant for SME $(P \leq 0.01)$, motor torque $(P \leq 0.01)$, and die pressure $(P \leq 0.05)$. The calculated SME ranged from $160.88 \pm 4.79$ to $511.21 \pm 11.08 \mathrm{~kJ} / \mathrm{kg}$,

\begin{tabular}{|c|c|c|c|c|c|c|c|c|c|}
\hline Level & SME & Motor Torque & Die Pressure & Expansion & Density & WSI & WAI & Hardness & Color \\
\hline$C$ & -346.038 & $30.603^{*}$ & $5672.985^{* *}$ & $8.307^{* *}$ & -0.016 & 72.249 & $-19.018^{*}$ & 82.825 & $96.667^{* *}$ \\
\hline$M$ & 22.078 & -0.443 & $-449.617^{* *}$ & -0.281 & -0.035 & -5.612 & $1.950^{* *}$ & -1.498 & -0.104 \\
\hline G & -8.350 & -0.230 & 9.890 & $0.222^{*}$ & $-0.083^{* *}$ & $5.021^{*}$ & -0.065 & $-5.451^{*}$ & -0.139 \\
\hline SS & $6.545^{* *}$ & 0.037 & -2.137 & -0.016 & 0.005 & 0.122 & 0.043 & -0.388 & $-0.030^{*}$ \\
\hline$M \times M$ & $-0.996^{*}$ & -0.041 & $9.440^{* *}$ & 0.004 & 0.003 & 0.171 & $-0.041^{* *}$ & 0.070 & 0.002 \\
\hline$G \times G$ & $-1.151^{* *}$ & $-0.051^{* *}$ & 0.485 & -0.001 & $0.002^{* *}$ & -0.050 & $-0.024^{* *}$ & $0.140^{*}$ & $0.021^{* *}$ \\
\hline$S S \times S S$ & $-0.010^{* *}$ & $0.000^{*}$ & -0.004 & 0.000 & 0.000 & 0.001 & 0.000 & 0.001 & $0.000^{*}$ \\
\hline$M \times G$ & $1.312^{* *}$ & $0.057^{* *}$ & $-1.173^{*}$ & $-0.012^{* *}$ & $0.004^{* *}$ & -0.152 & 0.009 & 0.124 & $-0.012^{* *}$ \\
\hline$M \times S S$ & -0.071 & 0.003 & $0.151^{* *}$ & 0.000 & $0.000^{* *}$ & -0.014 & 0.000 & -0.003 & 0.000 \\
\hline$G \times S S$ & -0.020 & -0.001 & 0.060 & 0.000 & $0.000^{*}$ & -0.008 & 0.001 & 0.002 & 0.000 \\
\hline$R^{2}$ & 0.961 & 0.953 & 0.984 & 0.891 & 0.831 & 0.795 & 0.886 & 0.759 & 0.981 \\
\hline$F$ & 55.062 & 44.643 & 138.441 & 18.159 & 10.930 & 8.602 & 17.206 & 6.991 & 116.450 \\
\hline Sig. $F$ & 0.000 & 0.000 & 0.000 & 0.000 & 0.000 & 0.000 & 0.000 & 0.000 & 0.000 \\
\hline
\end{tabular}

SME: Specific mechanical energy; WAI: Water absorption index; WSI: Water solubility index; C: Model constant; M, G and SS: Linear effects of moisture content, grape pomace, and screw speed, respectively; $M \times G$ : Interaction of moisture content and grape pomace; $M \times S S$ : Interaction of moisture content and screw speed; $M \times M$, $G \times$ G; SS $\times$ SS: Quadratic effects of moisture content, grape pomace, and screw speed, respectively.

* and ${ }^{* *}$ indicate significant at $P \leq 0.05$ and 0.01 respectively.

Table 2: Results of regression analysis for cornstarch grape pomace extrudates.

\begin{tabular}{|c|c|c|c|c|c|}
\hline Moisture (\%) & GP (\%) & Screw Speed (rpm) & SME (kJ/kg) & Motor Torque (Nm) & Die Pressure (psi) \\
\hline \multirow{8}{*}{16} & \multirow{2}{*}{0} & \multirow{2}{*}{200} & $404.6 \pm 4.51$ & $17.56 \pm 0.20$ & $814.00 \pm 4.57$ \\
\hline & & & $441.00 \pm 6.79$ & $19.14 \pm 0.29$ & $816.10 \pm 5.28$ \\
\hline & & \multirow{2}{*}{150} & $374.47 \pm 10.5$ & $21.67 \pm 0.16$ & $843.50 \pm 17.39$ \\
\hline & 5 & & $375.16 \pm 8.92$ & $21.71 \pm 0.52$ & $859.70 \pm 12.2$ \\
\hline & 5 & \multirow{2}{*}{250} & $511.21 \pm 11.08$ & $17.75 \pm 0.38$ & $730.90 \pm 16.86$ \\
\hline & & & $500.56 \pm 9.05$ & $17.38 \pm 0.31$ & $700.90 \pm 12.12$ \\
\hline & \multirow{2}{*}{10} & \multirow{2}{*}{200} & $409.20 \pm 4.14$ & $17.76 \pm 0.18$ & $852.50 \pm 5.74$ \\
\hline & & & $382.47 \pm 7.08$ & $16.6 \pm 0.31$ & $858.00 \pm 7.71$ \\
\hline \multirow{14}{*}{20} & \multirow{4}{*}{0} & \multirow{2}{*}{150} & $251.26 \pm 2.8$ & $14.54 \pm 0.16$ & $462.00 \pm 2.61$ \\
\hline & & & $233.80 \pm 2.42$ & $13.53 \pm 0.14$ & $460.50 \pm 2.56$ \\
\hline & & \multirow{2}{*}{250} & $376.14 \pm 13.59$ & $13.06 \pm 0.47$ & $402.80 \pm 3.34$ \\
\hline & & & $346.47 \pm 2.98$ & $12.03 \pm 0.10$ & $400.40 \pm 3.99$ \\
\hline & \multirow{6}{*}{5} & \multirow{6}{*}{200} & $365.19 \pm 4.38$ & $15.85 \pm 0.20$ & $464.90 \pm 6.22$ \\
\hline & & & $352.29 \pm 6.02$ & $15.29 \pm 0.26$ & $464.90 \pm 5.50$ \\
\hline & & & $359.66 \pm 4.34$ & $15.61 \pm 0.19$ & $470.20 \pm 4.94$ \\
\hline & & & $402.98 \pm 8.18$ & $17.49 \pm 0.36$ & $461.90 \pm 6.84$ \\
\hline & & & $358.51 \pm 10.75$ & $15.56 \pm 0.47$ & $471.60 \pm 6.06$ \\
\hline & & & $357.59 \pm 6.10$ & $15.52 \pm 0.26$ & $468.00 \pm 3.74$ \\
\hline & \multirow{4}{*}{10} & \multirow{2}{*}{150} & $284.78 \pm 5.42$ & $16.48 \pm 0.31$ & $502.60 \pm 2.74$ \\
\hline & & & $262.66 \pm 3.47$ & $15.2 \pm 0.20$ & $507.30 \pm 3.27$ \\
\hline & & \multirow{2}{*}{250} & $397.16 \pm 11.60$ & $13.79 \pm 0.40$ & $504.10 \pm 2.54$ \\
\hline & & & $347.34 \pm 7.29$ & $12.06 \pm 0.25$ & $507.3 \pm 4.63$ \\
\hline \multirow{8}{*}{24} & \multirow{2}{*}{0} & \multirow{2}{*}{200} & $197.46 \pm 3.86$ & $8.57 \pm 0.17$ & $453.00 \pm 2.70$ \\
\hline & & & $191.24 \pm 2.4$ & $8.3 \pm 0.10$ & $450.70 \pm 2.68$ \\
\hline & \multirow{4}{*}{5} & \multirow{2}{*}{150} & $160.88 \pm 4.79$ & $9.31 \pm 0.28$ & $437.40 \pm 2.19$ \\
\hline & & & $185.07 \pm 3.40$ & $10.71 \pm 0.20$ & $439.20 \pm 3.19$ \\
\hline & & \multirow{2}{*}{250} & $238.76 \pm 5.47$ & $8.29 \pm 0.19$ & $423.40 \pm 3.60$ \\
\hline & & & $256.04 \pm 5.11$ & $8.89 \pm 0.18$ & $423.30 \pm 2.96$ \\
\hline & \multirow{2}{*}{10} & \multirow{2}{*}{200} & $250.45 \pm 8.00$ & $10.87 \pm 0.35$ & $400.30 \pm 3.42$ \\
\hline & & & $294.23 \pm 5.06$ & $12.77 \pm 0.22$ & $396.10 \pm 3.33$ \\
\hline
\end{tabular}

Table 3: Results values of process response (SME, motor torque and pressure). 


\begin{tabular}{|c|c|c|c|c|c|c|c|c|c|}
\hline Level & SME & Motor Torque & Pressure & Expansion & Density & Hardness & WSI & WAI & Color (L) \\
\hline SME & 1 & $\ldots \ldots$ & $\ldots \ldots$ & $\ldots \ldots$ & $\ldots \ldots$ & $\ldots \ldots$ & $\ldots \ldots$ & $\ldots \ldots$ & $\ldots \ldots$ \\
\hline Motor Torque & $0.750^{* *}$ & 1 & $\ldots \ldots$ & $\ldots \ldots$ & $\ldots \ldots$ & $\ldots \ldots$ & $\ldots \ldots$ & $\ldots \ldots$ & $\ldots \ldots$ \\
\hline Pressure & $0.605^{\star}$ & $0.753^{* *}$ & 1 & $\ldots \ldots$ & $\ldots \ldots$ & $\ldots \ldots$ & $\ldots \ldots$ & $\ldots .$. & $\ldots \ldots$ \\
\hline Expansion & -0.024 & 0.028 & 0.050 & 1 & $\ldots \ldots$ & $\ldots \ldots$ & $\ldots \ldots$ & $\ldots \ldots$ & $\ldots \ldots$ \\
\hline Density & -0.008 & -0.148 & -0.125 & $-0.672^{*}$ & 1 & $\ldots \ldots$ & $\ldots \ldots$ & $\ldots .$. & $\ldots \ldots$ \\
\hline Hardness & 0.184 & 0.084 & 0.463 & -0.421 & 0.474 & 1 & $\ldots \ldots$ & $\ldots \ldots$ & $\ldots$ \\
\hline WSI & -0.149 & -0.119 & -0.142 & $0.749^{* *}$ & $-0.681^{*}$ & $-0.583^{*}$ & 1 & $\ldots \ldots$ & $\ldots .$. \\
\hline WAI & 0.036 & 0.075 & 0.049 & $-0.766^{* *}$ & 0.487 & 0.246 & $-0.766^{* *}$ & 1 & $\ldots .$. \\
\hline Color (L) & 0.210 & 0.163 & 0.443 & 0.377 & -0.068 & 0.497 & -0.019 & -0.396 & 1 \\
\hline
\end{tabular}

SME: Specific mechanical energy; WAI: Water absorption index; WSI: Water solubility index; L: Lightness.

* and ${ }^{* *}$ indicate significant at $P \leq 0.05$, and 0.01 , respectively.

Table 4: Cross-correlation values for cornstarch grape pomace extrudates.

and measured torque values ranged from $8.29 \pm 0.19$ to $21.71 \pm 0.52$ $\mathrm{Nm}$, while the mean calculated values for pressure were $396.10 \pm 3.33$ to $859.70 \pm 12.20$ psi (Table 3 ).

The feed moisture and GP levels affected all the process response parameters (Table 2). The values of SME, motor torque, and pressure were lower at higher feed moisture and GP levels (Table 3). The feed moisture and pomace affect the melt viscosity of the material being processed $[18,19]$. The main reason for lower values of the process parameters at elevated feed moisture levels is reduction in the viscosity of the melt inside the extruder. Low viscosity melt faces less resistance in the screws and thus will be easily pushed out through the extruder with minimum energy input. It is likely that the inclusion of the GP disrupted the starch melt and contributed to the decrease in viscosity by acting as lubricant inside the extruder, which is seen in other studies $[18,19]$. A lower melt viscosity due to GP could account for the lower SME, motor torque and pressure observed in our study. This trend was also in line with reduced expansion of the extrudates at a higher level of GP (10\%) and moisture content (24\%). Further, the SME integrates torque, screw speed, and pressure. The SME, motor torque, and pressure, values were low at high moisture content via regression analysis (Table 2). These results were coincided with the correlation results, which showed that SME, motor torque and pressure positively correlated to each other (Table 4). Increase in screw speed increased SME while the motor torque decreased (Table 2). At GP level of 5\%, the SME increased with the increasing screw speed and the decreasing feed moisture level (Figure 1). Generally, with increased screw speed, the SME increases. It is because increasing screw speed applies increased shear to the material being processed, resulting in greater SME input and decrease in motor torque. This is associated with decreased viscosity due to degradation of the starch in the material being processed $[18,19,30]$.

\section{Product response}

Expansion ratio: The ER of cornstarch extrudates with GP ranged from $2.06 \pm 0.12$ to $3.83 \pm 0.14$. ER was found to be most dependent on GP and feed moisture levels, as shown by the regression analysis (Table $2)$. GP had a positive linear effect $(P \leq 0.05)$ on the ER, along with a negative interactive effect $(P \leq 0.01)$ in combination with moisture. It was observed in the regression response surface plot (Figure $2 \mathrm{~A}$ ) that increased feed moisture led to significant reduction in ER. As explained earlier, the high moisture level in the feed led to a reduction in the SME that could cause reduced physicochemical transformation of starch, and hence reduced the ER. Moreover, the post expansion collapse of cells at the die exit due to decrease in temperature, and migration of additional moisture from inside to the outside in expanding starch reduced the ER. Previous researchers also found an inverse relation between the ER and feed moisture [25,39], which are in line with our observations.

Addition of GP (5\%) at low feed moisture (16\%) resulted in an increase in the ER compared to the control with $0 \%$ GP, while the expansion ratio decreased with the addition of GP (10\%) at a high feed moisture (24\%) (Figure 2A,2B). The expansion phenomenon of the extruded products is mainly based on the flashing off of the steam that expands the starch matrix, forming a porous product, along with the die swell property of the materials $[24,25,40]$. Traditionally, it was thought that addition of fiber reduces the ER of the final product [39]. However, the results suggest that instead of the GP being inert at low moistures, it is playing an active role either through the fiber, or the other components of the GP. It is possible that the fiber could have played an active role at $5 \%$ GP by being uniformly distributed in the starch matrix, which would allow maximum expansion, with fiber not disrupting the expanded starch structure. This trend is prominent in the carrot pomace and cherry pomace incorporated cornstarch expended products $[18,19]$. Other possibilities could be that sugar in addition to fiber in GP might have more specific effects. Sugar crystals act as filler at lower feed moisture and enhances expansion of the extrudates [41].
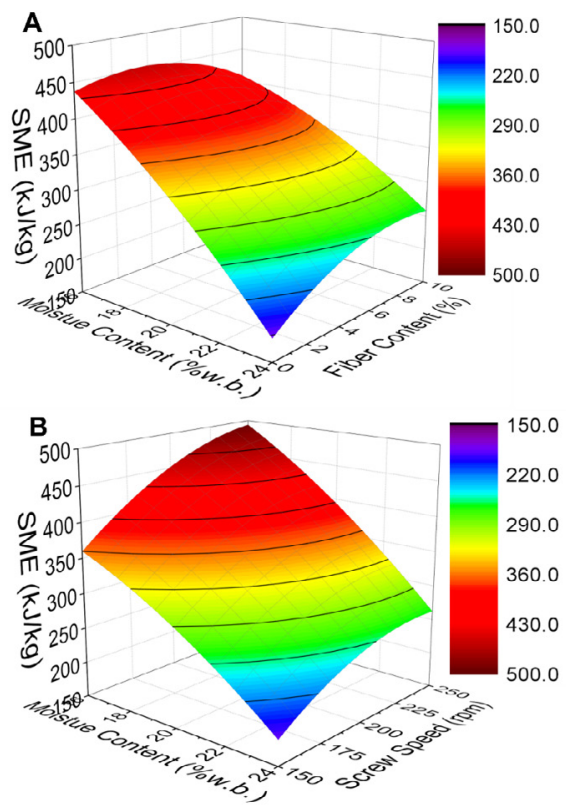

Figure 1: Specific mechanical energy (SME) response surface of cornstarch extrudates with different moisture content, grape pomace content, and screw speed. (A) Feed moisture vs grape pomace, and (B) Feed moisture vs screw speed. 
Fiber in GP might have acted as a nucleating agent allowing cornstarch to trap more air cells by surrounding them firmly, while sugars in GP at low feed moisture might have enhanced the film forming effect by allowing bubble walls to be stabilized, resulting in larger porous structure. On the other hand, high GP and high moisture level has the tendency to disturb the starch matrix and the GP distribution during extrusion. This could have affected the expansion phenomenon such as collapsing of the cells due to aggregated GP in different spots of the starch [39] and plasticizing effect of sugars on starch [41] resulting in the reduction of the ER. Similarly, cherry pomace at $15 \%$ in cornstarch significantly reduces the ER compared to control [18]. Our findings are opposite to that of Altan and colleagues who found a decrease in the expansion with up to 6\% GP of barley flour extrudates [16]. This difference could be due to difference in the raw material ingredients, as well as processing parameters, which is also evident from our previous studies on carrot and cherry pomace incorporation in cornstarch $[18,19]$. Overall, this suggests that there was positive active interaction between the GP constituents (sugars and fiber) and starch during extrusion that enhanced the expansion.

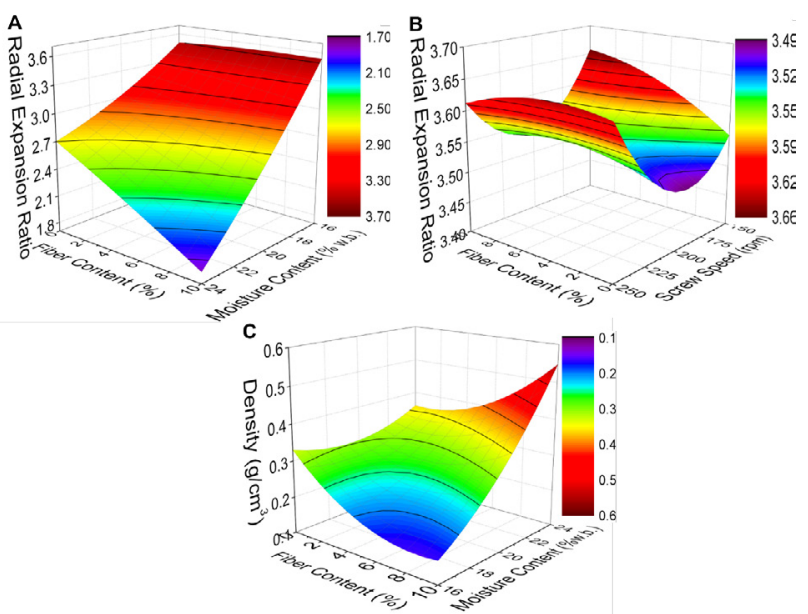

Figure 2: Product response characteristics of cornstarch extrudates processed with different moisture content, grape pomace content and screw speed. Expansion ratio $(A \& B)$, Unit density $(C)$.
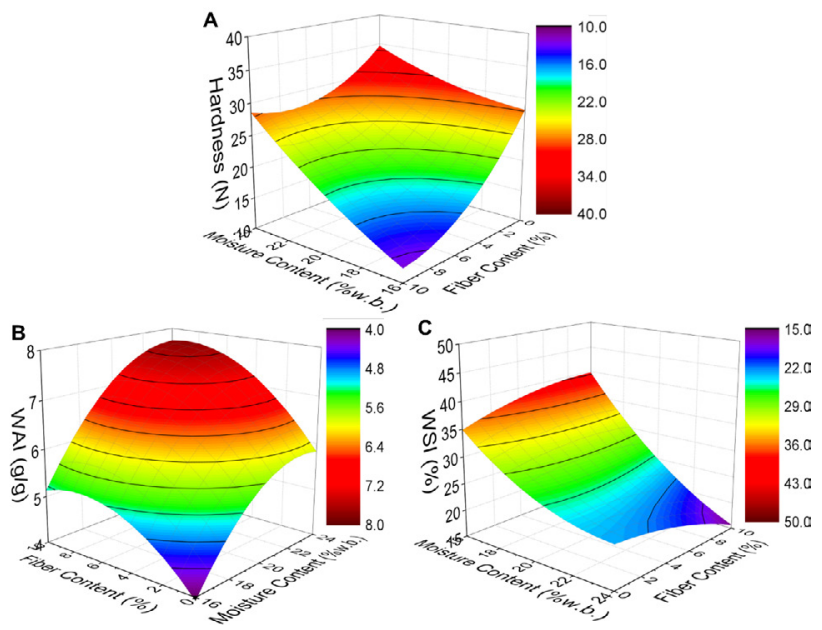

Figure 3: Product response characteristics of cornstarch extrudates processed with different moisture content, grape pomace content, and screw speed. Hardness (A), WAI (B), and WSI (C).
Unit density: Unit density is inversely proportional to expansion. Unit density values ranged from $0.11 \pm 0.00$ to $0.58 \pm 0.13 \mathrm{~g} / \mathrm{cm}^{3}$ for all extrudates. The regression analysis (Table 2) indicated that the linear and quadratic effect of GP significantly affected the unit density of the extrudates. The individual two-way interactive effects of all the variables: moisture, GP, and screw speed positively affected the unit density of the extrudates $(P \leq 0.01)$. Increase in GP resulted in low unit density of the extrudates at a constant screw speed, while unit density of the extrudates decreased with decrease in moisture content (Figure 2C). This trend of the unit density can be attributed to the same factors that increased the ER at low feed moisture. Also with the inclusion of $\mathrm{GP}$, the starting flour mix became less dense as GP unit density $(0.48$ $\left.\pm 0.01 \mathrm{~g} / \mathrm{cm}^{3}\right)$ was significantly lower than that of cornstarch $(0.78$ $\left.\pm 0.02 \mathrm{~g} / \mathrm{cm}^{3}\right)$. Further, the ER was negatively correlated with unit density (Table 4). Lower density and higher expansion are considered as favorable characteristics of extruded products. The GP levels effect on the unit density, are opposite to those found for extruded product of barley flour with GP [16], and corn flour with pineapple pomace [28], which could be due to the unique physical properties of GP and cornstarch.

Hardness: Hardness is a measure of the amount of force applied to break the sample. Lower the hardness the crispier and crunchier the extruded product is typically. GP had a significant negative linear, and significant positive quadratic effect on hardness (Table 2). The response surface plot for the GP and moisture content at fixed screw speed $(200 \mathrm{rpm})$ is shown in Figure 3A. For low feed moisture (16\%), increase in the GP led to lower hardness than the control samples. This low hardness, is anticipated from the fact that low density and high expansion correlates with low hardness [32,42]. These results are in line with unit density, which had a positive correlation with hardness (Table 1). Similar results are found in barley flour extrudates with GP [16] and the chick pea flour extruded snack foods [42]. The decrease in feed moisture resulted in an increased melt viscosity and SME, while the GP incorporation would result in uniform distribution of GP in cornstarch, forming more air cells with a final porous structure, which could decrease hardness. The lower hardness with GP inclusion (at 5\%) can provide a crispier texture than only cornstarch extrudates when extruded under low moisture condition, in addition to health beneficial attributes.

\section{Water absorption index (WAI) and water solubility index (WSI)}

WAI measures the volume occupied by starch after swelling in excess water, which can indicate the starch integrity in water after the extrusion processing [43]. Feed moisture had positive linear, and negative quadratic effect while GP had positive quadratic effect on the WAI (Table 2). According to the response surface plots (Figure 3B) with increased feed moisture and GP, the WAI was lowered (screw speed $200 \mathrm{rpm}$ ). A similar trend was observed for GP (5\% and 10\%) levels that with an increase in moisture and screw speed heightened the WAI. At each feed moisture level (16, 20 or $24 \pm 0.2 \%)$, the increase in screw speed resulted in lower WAI values, while the inclusion of GP resulted in higher WAI values. As increased screw speed results in an increased SME, that would ultimately result in more breakdown of the starch. This suggests that high screw speed renders more soluble products [17]. GP contains fiber, carbohydrates, and proteins components that can provide more hydrophilic forces to compete for water than the starch [16], which could be another explanation to the higher WAI found in extrudates with GP. WAI is an indicator of the hydrophilic groups and their gel-forming capability within the starch matrix [43]. High WAI values indicate that the extrudates can hold 
water with lesser solubility. This is a valuable property in processing breakfast cereal products, which helps to increase bowl life.

WSI measures soluble polysaccharides liberated from the starch after extrusion process, indicating molecular components degradation during extrusion [43]. WSI values ranged from $14.23 \pm 3.85$ to 72.99 $\pm 2.57 \%$ for all the extrudates. GP exhibited positive linear effect on WSI (Table 2). At screw speed of $200 \mathrm{rpm}$, WSI had inverse relation with GP and feed moisture as shown by the response surface plot (Figure 3C). At 16\% moisture level, WSI exhibited a direct trend with increased screw speed, and an inverse trend with 5\% GP inclusion. These results are in line with the previously reported WSI range [17]. The lower WSI of GP extrudates was consistent with their higher WAI, which was further proved by the negative correlation $(-0.76)$ between WSI and WAI (Table 1). Lower values of WSI are often associated with the less dextrinization of starch during extrusion. Addition of GP provides insoluble fiber and other hydrophilic groups that can interact with starch to reduce the overall gelatinization, and hold water instead of being solubilized [27,43]. In fact cherry pomace in swelled starch granules trapes water and lowers WSI [18]. However, soluble sugars within the GP could also lead to an increase in WSI since they are more dextrinized components. The overall WSI values are likely a balance between the WSI from the starch components and from the GP components. This is likely why WSI is seen to increase with GP inclusion at low moistures, but decrease at high moistures. The lower moistures favor more mechanical breakdown in the starch leading to dextrinization as opposed to at higher moisture. It is also relevant from the high SME as it enhanced the starch breakdown and hence increased WSI. The low WSI value is favorable for the extruded product to maintain the structure; indicating GP can be utilized in the development of direct expanded breakfast cereals with crispier textures and longer bowl life.

\section{Color}

The regression analysis for the lightness $(\mathrm{L})$ is shown in Table 2. GP level had a prominent effect on color parameters $(\mathrm{L}, a, b)$ with positive linear effect and quadratic effects on $a$, and $b$ values $(P \leq 0.01)$. Screw speed had a linear and quadratic effect on $\mathrm{L}$ and $b$ values $(P \leq 0.01)$. In addition, the $\mathrm{L}$ value was also affected by interactive effect of feed moisture and GP level $(P \leq 0.01)$. Reduction in lightness with increasing GP level was observed at screw speed of $200 \mathrm{rpm}$. These findings are in agreement with those of Altan and colleagues who also found a reduction in lightness with GP inclusion [16]. The low L value with increased GP could be due to the browning Maillard reaction and caramelization due to the presence of more simple sugars and proteins in the GP compared to cornstarch. Increased $a$ and $b$ values could also be due to the yellowish pigments in the GP and its heat degraded products.

\section{Total polyphenolic content of GP extrudates extracts}

Based on the quality analysis of cornstarch extrudates with GP, the extrudates at low feed moisture (16\%) conditions were further chosen for TPC quantification. TPC of the dried GP was $58.15 \pm 5.21 \mathrm{mg} \mathrm{GAE} / \mathrm{g}$ DW. TPC of the raw material mixes at $16 \%$ feed moisture with $0 \%, 5 \%$ and $10 \%$ GP were beyond detection level, $1.12 \pm 0.03$, and $1.89 \pm 0.06$ mg GAE/g DW, respectively. The loss of polyphenolics depended on the extrusion process combinations. TPC retention in the extrudates with 5\% GP was $74.10 \%$ (150 rpm), and $78.57 \%$ (250 rpm), while TPC in products with $10 \%$ GP under $200 \mathrm{rpm}$ had no significant loss (Figure 4A). Results indicated that most of the polyphenolics retained in extrusion processing and thus could contribute to the nutritional quality of the extrudates. It has been reported that heat (baking) above $180^{\circ} \mathrm{C}$ negatively affects the TPC of the grape seed flour [15]. The difference may be attributed to the short residence time usually less than $45 \mathrm{~S}$ in extrusion processing [44] as opposed to significantly longer baking times. In support, recently, we found that extrusion technology has a very minimal effect on the loss of water soluble TPC in cherry pomace incorporated in cornstarch, with no significant decrease of TPC in the extruded product [18].

\section{Effect of extrusion on the total antioxidant activities of GP extrudates}

Based on the percent retention of TPC in extrudates with $5 \% \mathrm{GP}$, we further accessed the possible influence of extrusion processing on GP functionality. We evaluated the antioxidant activity of the 5\% GP level before and after extrusion process. The antioxidant activity of the $5 \%$ GP at $16 \%$ feed moisture before extrusion was $22.15 \pm 0.03 \mu \mathrm{g} \mathrm{GAE} / \mathrm{g}$ $\mathrm{DW}$, after extrusion at $150 \mathrm{rpm}$ was $21.80 \pm 0.21 \mu \mathrm{g} \mathrm{GAE} / \mathrm{g} \mathrm{DW}$, and at $250 \mathrm{rpm}$ was $21.31 \pm 0.38 \mu \mathrm{g}$ GAE/g DW. The antioxidant activity and DPPH free radical scavenging activity of extrudates with 5\% GP at $150 \mathrm{rpm}$ maintain the same as the raw material before extrusion with a 98\% retention (Figure 4B,4C). Our findings showed that functionality of the GP bioactives could be maintained if the extrusion processing was conducted at an optimal condition, and hence GP incorporation enhances the nutritional value of extrudates. Previously, the baking process of grape seed flour significantly reduced its antioxidant activity [15]. The difference in time duration of exposure to heat which is less than $45 \mathrm{~s}$ in extrusion processing [44] can explain the retention of antioxidant activity of the GP extrudates. Based on the physicochemical quality of the extruded products with GP, the addition of 5\% GP level in cornstarch processed at $16 \%$ moisture level and $150 \mathrm{rpm}$ screw speed is promising to produce healthy extrudates.

\section{Effect of GP extrudates extracts on intracellular ROS production in Caco-2 human colonic epithelial cells}

Furthermore, we examined the protective effect of GP extrudates against ROS production in human colonic epithelial cells using poplyphenolic extract prepared from GP raw mixes and extrudates. Hydrogen peroxide $\left(\mathrm{H}_{2} \mathrm{O}_{2}\right)$ treatment induced enhanced ROS production in Caco-2 cells, which was mitigated by the GP polyphenolic extract treatment (Figure 4D). In fact, GP polyphenolics quenched ROS production in Caco-2 cells bringing it lower than the control with no detrimental effect of extrusion cooking. GP polyphenolics possess antioxidant as well as anti-infla mmatory effects with a well-established health beneficial effect on intestine $[9,12,45,46]$. These finding suggest that GP can be used as adjunctive ingredient in the production of healthy extrusion based cornstarch expended products.

\section{Conclusion}

Grape pomace incorporation in combination with feed moisture greatly affected the expansion quality of cornstarch extrudates. The $5 \%$ grape pomace level at the $16 \%$ feed moisture and $150 \mathrm{rpm}$ resulted in enhanced expansion with substantial retention of TPC, total antioxidant activity in the cornstarch extrudates. This research can be applied in the making of corn starch expanded products with good nutritional value, which will enhance usage of this byproduct maximizing revenue of expending grape and wine industry. Further research on the sensory characteristics and physical and chemical interactions of GP with cornstarch need to be investigated.

\section{Acknowledgement}

This work was financially supported by Washington State University new 

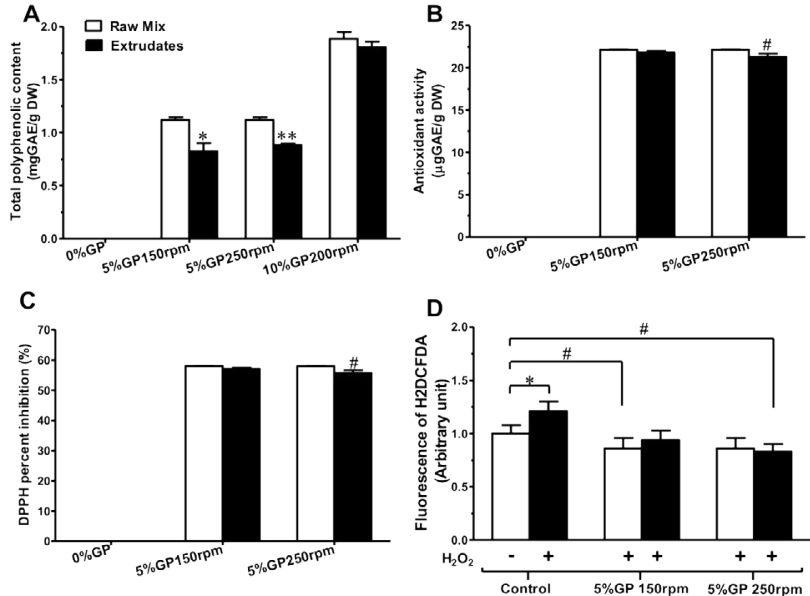

GP: Grape Pomace; Mean \pm SEM; $\mathrm{n}=3 ;$ *: $P \leq 0.05 ; * *$ : $P \leq 0.01$; \#: $P \leq 0.10$

Figure 4: Total phenolic content, antioxidant activity, and effect on ROS production of raw material mixes and cornstarch extrudates with GP processed at $16 \%$ feed moisture content and $150-250$ rpm screw speed. Total phenolic content (A), Antioxidant actvity (B), Percent DPPH inhibition (C), and intracellular reactive oxygen species (ROS) scavanging activity in $\mathrm{CaCO}_{2}$ cells.

faculty seed grant (10A-3057-9906) to Dr. Mei-Jun Zhu. We thank the Woodward Canyon Winery (Lowden, WA) for providing the grape pomace and the Tate \& Lyle (Decatur, IL, US) for providing cornstarch for the experiments. We also thank to Frank Younce and Bhim Thapa at Washington State University for their help during the project.

\section{References}

1. FAOSTAT (2012) Agricultural production domain online. Food and Agricultural Organization of the United Nations.

2. Kammerer D, Gajdos Kljusuric J, Carle R, Schieber A (2005) Recovery of anthocyanins from grape pomace extracts (Vitis vinifera L. Cv. Cabernet Mitos) using a polymeric adsorber resin. Eur Food Res Technol 220: 431-437.

3. Woodard F (2001) Industrial waste treatment handbook. ButterworthHeinemann, USA.

4. Aghsaghali MA, Sis MN, Mansouri H, Razeghi ME, Safaei AR, et al. (2011) Estimation of the nutritive value of tomato pomace for ruminant using in vitro gas production technique. Africa J Biotechnol 10: 6251-6256.

5. Fontana AR, Antoniolli A, Bottini R (2013) Grape pomace as a sustainable source of bioactive compounds: extraction, characterization, and biotechnological applications of phenolics. J Agri Food Chem 61: 8987-9003.

6. Bravi M, Spinoglio F, Verdone N, Adami M, Aliboni A, et al. (2007) Improving the extraction of $\alpha$-tocopherol-enriched oil from grape seeds by supercritical $\mathrm{CO}_{2}$. Optimisation of the extraction conditions. J Food Eng 78: 488-493.

7. Deng Q, Penner MH, Zhao Y (2011) Chemical composition of dietary fiber and polyphenols of five different varieties of wine grape pomace skins. Food Res Int 44: 2712-2720.

8. Rockenbach II, Rodrigues E, Gonzaga LV, Caliari V, Genovese MI, et al. (2011) Phenolic compounds content and antioxidant activity in pomace from selected red grapes (Vitis vinifera L. and Vitis labrusca L.) widely produced in Brazil. Food Chem 127: 174-179.

9. Bibi S, Kang Y, Yang G, Zhu M (2016) Grape seed extract improves small intestinal health through suppressing inflammation and regulating alkaline phosphatase in IL-10-deficient mice. J Funct Foods 20: 245-252.

10. Zhou K, Raffoul JJ (2012) Potential anticancer properties of grape antioxidants J Oncol.

11. Feringa HH, Laskey DA, Dickson JE, Coleman $\mathrm{Cl}$ (2011) The effect of grape seed extract on cardiovascular risk markers: a meta-analysis of randomized controlled trials. J America Diet Asso 111: 1173-1181.

12. Wang H, Xue $Y$, Zhang H, Huang Y, Yang G, et al. (2013) Dietary grape seed extract ameliorates symptoms of inflammatory bowel disease in IL10-deficient mice. Mol Nutr Food Res 57: 2253-2257.
13. Pazos M, Gallardo JM, Torres JL, Medina I (2005) Activity of grape polyphenols as inhibitors of the oxidation of fish lipids and frozen fish muscle. Food Chem 92: 547-557.

14. Tseng A, Zhao Y (2013) Wine grape pomace as antioxidant dietary fibre for enhancing nutritional value and improving storability of yogurt and salad dressing. Food Chem 138: 356-365

15. Ross CF, Hoye CJ, Fernandez-Plotka VC (2011) Influence of heating on the polyphenolic content and antioxidant activity of grape seed flour. J Food Sci 76: 884-890.

16. Altan A, McCarthy KL, Maskan M (2008) Twin-screw extrusion of barleygrape pomace blends: Extrudate characteristics and determination of optimum processing conditions. J Food Eng 89: 24-32.

17. Altan A, McCarthy KL, Maskan M (2009) Effect of extrusion cooking on functional properties and in vitro starch digestibility of barley-based extrudates from fruit and vegetable by-products. J Food Sci 74: 77-86.

18. Wang S, Kowalski RJ, Kang Y, Kiszonas AM, Zhu M-J, et al. (2017) Impacts of the Particle Sizes and Levels of Inclusions of Cherry Pomace on the Physical and Structural Properties of Direct Expanded Corn Starch. Food Bioprocess Technol.

19. Kaisangsri N, Kowalski RJ, Wijesekara I, Kerdchoechuen O, Laohakunjit $N$ et al. (2016) Carrot pomace enhances the expansion and nutritional quality of corn starch extrudates. LWT - Food Sci Technol 68: 391-399.

20. Khanal RC, Howard LR, Prior RL (2009) Procyanidin content of grape seed and pomace, and total anthocyanin content of grape pomace as affected by extrusion processing. J Food Sci 74: 174-182.

21. Ganjyal GM, Hanna MA, Jones DD (2003) Modelling selected properties of extruded waxy maize cross-linked starches with neural networks. J Food Sci 68: 1384-1388.

22. Gu L, House SE, Rooney LW, Prior RL (2008) Sorghum extrusion increases bioavailability of catechins in weanling pigs. J Agri Food Chem 56: 1283-1288.

23. Brennan MA, Derbyshire E, Tiwari BK, Brennan CS (2013) Ready-to-eat snack products: the role of extrusion technology in developing consumer acceptable and nutritious snacks. Int J Food Sci Technol 48: 893-902.

24. Chinnaswamy R, Hanna MA (1988) Relationship between amylose content and extrusion-expansion properties of corn starches. Cereal Chem J 65: 138-143.

25. Ganjyal GM, Hanna MA (2006) Role of blowing agents in expansion of highamylose starch acetate during extrusion. Cereal Chem J 83: 577-583.

26. Shevkani K, Kaur A, Singh G, Singh B, Singh N (2013) Composition, rheological and extrusion behaviour of fractions produced by three successive reduction dry milling of corn. Food Bioprocess Technol 7: 1414-1423.

27. Kumar N, Sarkar BC, Sharma HK (2010) Development and characterization of extruded product using carrot pomace and rice flour. Int J Food Eng 6: 1-24.

28. Selani MM, Brazaca SG, Dos Santos Dias CT, Ratnayake WS, Flores RA, et al. (2014) Characterisation and potential application of pineapple pomace in an extruded product for fibre enhancement. Food Chem 163: 23-30.

29. AOAC (2003) Official methods of analysis of AOAC. Association of officia analytical chemists, Gaithersburg, USA.

30. Godavarti S, Karwe MV (1997) Determination of specific mechanical energy distribution on a twin-screw extruder. J Agri Eng Res 67: 277-287.

31. Anderson R, Conway H, Pfeifer V, Griffin E (1969) Gelatinization of corn grits by roll-and extrusion-cooking. Cereal Sci Tod 14: 4.

32. Kowalski RJ, Morris CF, Ganjyal GM (2015) Waxy soft white wheat: Extrusion characteristics and thermal and rheological properties. Cereal Chem J 92: 145-153.

33. Zhang S, Zhu M (2015) Characterization of polyphenolics in grape pomace extracts using ESI Q-TOF MS/MS. J Food Sci Nutri 1: 001.

34. Singleton VL, Rossi JJA (1965) Colorimetry of total phenolics with phosphomolybdic-phosphotungstic acid reagents. America J Enology Viticultur 16: $144-158$.

35. Masuda T, Yonemori S, Oyama Y, Takeda Y, Tanaka T, et al. (1999) Evaluation of the Antioxidant Activity of Environmental Plants: Activity of the Leaf Extracts from Seashore Plants. J Agri Food Chem 47: 1749-1754.

36. Bellion P, Olk M, Will F, Dietrich H, Baum M, et al. (2009) Formation of hydrogen 
Citation: Bibi S, Kowalski RJ, Zhang S, Ganjyal GM, Zhu MJ (2017) Stability and Functionality of Grape Pomace Used as a Nutritive Additive During Extrusion Process. J Food Process Technol 8: 680. doi: 10.4172/2157-7110.1000680

peroxide in cell culture media by apple polyphenols and its effect on antioxidant biomarkers in the colon cell line HT-29. Mol Nutr Food Res 53: 1226-1236.

37. Seth D, Badwaik LS, Ganapathy V (2015) Effect of feed composition, moisture content and extrusion temperature on extrudate characteristics of yam-cornrice based snack food. J Food Sci Technol 52: 1830-1838.

38. Camire ME, King CC (1991) Protein and fiber supplementation effects on extruded cornmeal snack quality. J Food Sci 56: 760-763.

39. Ganjyal GM, Reddy N, YQ Y, Hanna MA (2004) Biodegradable packaging foams of starch acetate blended with corn stalk fibers. J Appl Polymer Sci 93: 2627-2633.

40. Launay B, Lisch JM (1983) Twin-screw extrusion cooking of starches: Flow behaviour of starch pastes, expansion and mechanical properties of extrudates. J Food Eng 2: 259-280.

41. Carvalho CW, Mitchell JR (2000) Effect of sugar on the extrusion of maize grits and wheat flour. Int J Food Sci Technol 35: 569-576.
42. Meng X, Threinen D, Hansen M, Driedger D (2010) Effects of extrusion conditions on system parameters and physical properties of a chickpea flourbased snack. Food Res Int 43: 650-658.

43. Gonzalo de Gutierrez MV, Gomez MH (1987) A model for the extrusion of a corn: Soybean blend. Arch Latinoam Nutr 37: 494-502.

44. Ganjyal G, Hanna M (2002) A review on residence time distribution (RTD) in food extruders and study on the potential of neural networks in RTD modeling J Food Sci 67: 1996-2002.

45. Yang G, Wang H, Kang Y, Zhu M (2014) Grape seed extract improves epithelial structure and suppresses inflammation in ileum of IL-10-deficient mice. Food Funct 5: 2558-2563.

46. Yang G, Xue Y, Zhang H, Du M, Zhu M (2015) Favourable effects of grape seed extract on intestinal epithelial differentiation and barrier function in IL10deficient mice. Br J Nutr 114: 15-23. 